\title{
Diffuse Calcification of the Airways
}

Joanne Wright, M.D., FRCP, Edward Jones, M.D., FRCP

Department of Pathology, St. Paul's Hospital (JW), and Department of Pathology, Vancouver Hospital (EJ), Vancouver, British Columbia

\begin{abstract}
Airway calcification is usually restricted to the cartilaginous conducting portion of the bronchial tree. Alternatively, calcification of the alveoli is a relatively common consequence of calcium and phosphate imbalance. We wish to report an unusual case in which diffuse calcification of the entire bronchial tree, absent alveolar calcification, was identified in a patient with renal dysfunction. Pathologists should not exclude metastatic calcification when considering the etiology of bronchial calcification.
\end{abstract}

\section{KEY WORDS: Airway calcification, Calcium.}

Mod Pathol 2001;14(7):717-719

Although localized areas of calcification within the bronchial tree can be seen in a reaction to inflammation or trauma and calcification in the cartilaginous airways can be found in conditions such as relapsing perichondritis and tracheopathia osteoplastica, it is unusual to find diffuse calcification of the entire bronchial tree. By contrast, metastatic calcification of the alveolar parenchyma is a clearly recognized complication of chronic renal disease. We describe the unusual, and heretofore undocumented, finding of generalized calcification of the airways, with no alveolar wall calcification in a patient with longstanding renal failure and recent transplantation.

\section{MATERIALS AND METHODS}

\section{Case Presentation}

The patient was a 40 -year-old female who had received a renal transplant in the month previous because of diabetic renal failure. She was readmitted to hospital with sepsis secondary to abdominal viscus perforation. While in the hospital, her acid base status fluctuated, with episodes of respiratory

Copyright () 2001 by The United States and Canadian Academy of Pathology, Inc.

VOL. 14, NO. 7, P. 717, 2001 Printed in the U.S.A

Date of acceptance: February 27, 2001.

Address reprint requests to: Joanne Wright, Department of Pathology,

2211 Wesbrook Mall, Vancouver, British Columbia, Canada V6T 2B5;

e-mail: jlwright@interchange.ubc.ca; fax: 604-822-7104. and metabolic acidosis. Her serum calcium levels ranged between 2.65 and $2.79 \mathrm{mmol} / \mathrm{L}$ (normal values, 2.00 to $2.60 \mathrm{mmol} / \mathrm{L}$ ), and her serum phosphate ranged between 1.20 and $2.10 \mathrm{mmol} / \mathrm{L}$ (normal values, 0.80 to $1.45 \mathrm{mmol} / \mathrm{L}$ ). Serum magnesium levels were within normal limits, with a range of 0.80 to $1.00 \mathrm{mmol} / \mathrm{L}$. Plain-film chest radiographs were unremarkable. The patient succumbed as a result of sepsis, approximately 1 month after transplant.

\section{Gross Findings}

At autopsy, the large airways appeared unremarkable. The small airways in the lung sections had a coarse texture, and the bifurcations of the respiratory bronchioles were prominent (Fig. 1). There were no areas of consolidation or hemorrhage.

\section{Microscopic Findings}

Microscopic sections were obtained from multiple sites along the bronchial tree and stained with hematoxylin and eosin or Von Kossa. The larger cartilaginous airways had areas of calcification that were most marked in the subepithelial connective tissue space and the basement membrane (Fig. 2). These deposits were both linear and spiculated in form, with focal formation of calcific islands and occasional calcospherites. There was calcification of the cartilage plates, both in the plates themselves, and along the fibrous tissue adjacent to the perichondrium. The membranous and respiratory bronchioles had a striking degree of linear and granular calcification, present circumferentially in the subepithelial compartment. Calcification extended into the alveolar ducts, but there was no associated alveolar calcification in any of the sections obtained from the lung slices (Fig. 3). Neither the larger elastic, nor the large to small muscular arteries contained calcific deposits.

Because visceral calcification can be divided into two broad types based on distribution of calcification and associated with different chemical compositions (see Discussion), we digested lung tissue in bleach and collected the particulate fraction on 


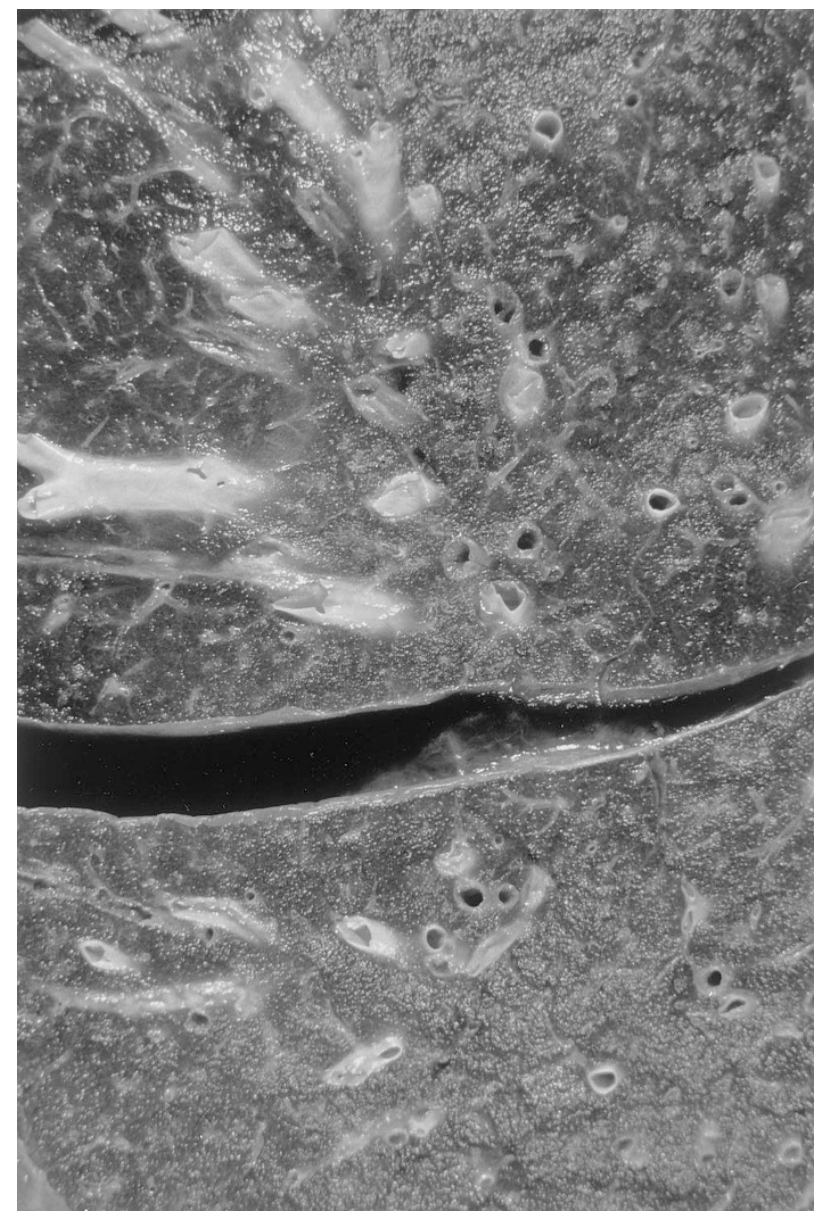

FIGURE 1. A cross section of inflated lung demonstrating the prominence of the small membranous and respiratory airways. Although the airways were granular, the alveolar parenchyma was normal to palpation.

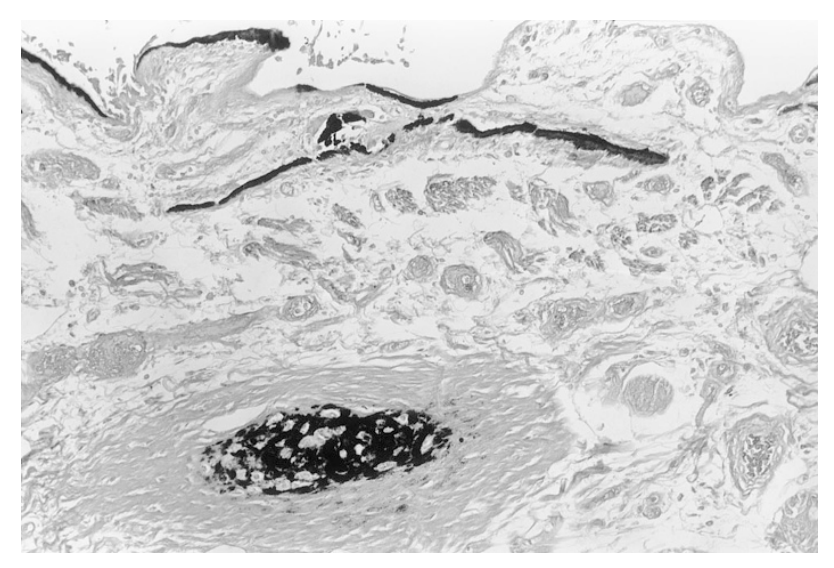

FIGURE 2. There are linear calcific deposits in the basement membrane and in the sub-epithelial fibrous tissue of the cartilagenous bronchi. Von Kossa stain, $160 \times$.

Millipore filters as described in Ingram et al. (1) in an attempt to determine the composition of the calcific material. Particles were then transferred to coated electron microscope grids and examined in an analytical electron microscope using energydispersive X-ray spectroscopy to determine the rel-

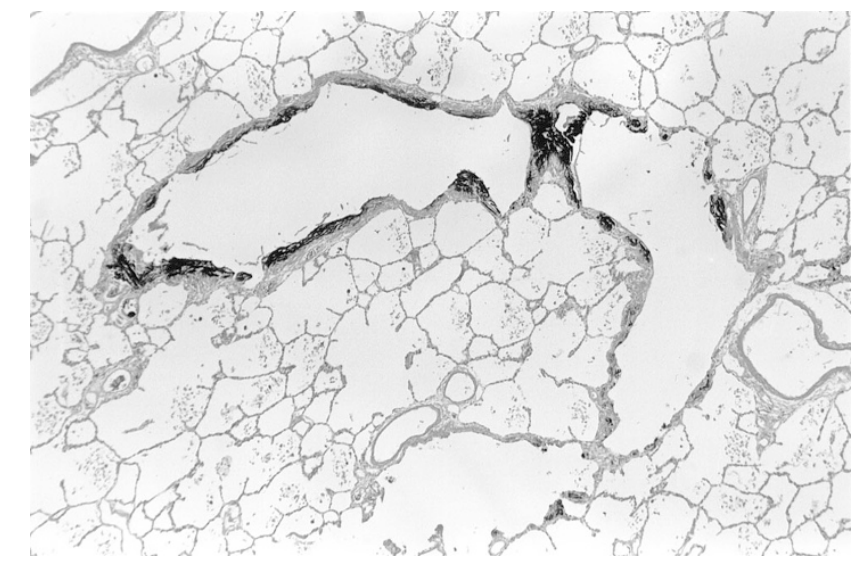

FIGURE 3. Calcification of the membranous and respiratory bronchiolar wall is marked, and there is extension into the alveolar ducts. The alveolar septa do not show any calcific deposits. Von Kossa stain, $40 \times$.

ative amounts of magnesium, phosphorus, and calcium. A mean Ca:Mg:P molar ratio of 5:1:4 was obtained.

\section{DISCUSSION}

Calcification and/or ossification is frequently seen in the lungs but usually occurs as isolated findings in relationship to healed areas of inflammation and is termed as dystrophic calcification. In the larger airways, the cartilage can become calcified as an age effect, or uncommonly, diffuse metaplastic bone formation can occur in the subepithelium, a process known as tracheobroncheopathia osteoplastica (2).

In the process known as metastatic calcification, calcium salts are deposited as a result of an imbalance in the saturation of calcium and phosphate, resulting in the deposition of $(\mathrm{CaMg})_{3}\left(\mathrm{PO}_{4}\right)_{2}$, known as magnesium whitlockite, with a Ca:Mg:P molar ratio of 4.9:1:4.6, or hydroxyapatite $\left(\mathrm{Ca}_{10}\left(\mathrm{PO}_{4}\right)_{6}(\mathrm{OH})_{2}\right)$, with a molar ratio of $30: 1: 18$. Whereas the former composition is found in visceral calcification, the latter is generally demonstrated in nonvisceral extraosseous calcification (3, 4); both are well described as a consequence of chronic renal disease (3-6). Nonvisceral calcification is generally found in the arteries and veins, in the subcutaneous tissues, and around tendons and joints. By contrast, visceral calcification is seen as deposits in the kidney, heart, stomach, muscle, and lung. Pulmonary visceral calcification is characterized by calcific depositions within the alveolar interstitium distorting the alveolar capillaries and occasionally affecting the pulmonary veins and arteries, with incrustation of the elastic laminae. In the most severe cases, almost all alveolar septa are involved, and the bronchi and bronchioles are also 
occasionally involved (4), whereas in the less severe cases, only the alveoli are involved.

Although, in general, calcification is found in patients with imbalances of serum calcium, phosphate, and magnesium, these alterations have not always been identified, and progressive calcification in the face of normal values has also been reported (7). In addition, visceral calcification appears to be less dependent upon the product of calcium and phosphate and more upon the levels of magnesium $(3,8,9)$. The present patient did have abnormally increased calcium and phosphate levels but had normal magnesium levels; nevertheless, she would be considered susceptible to pulmonary calcinosis. It is also important to note that other than diabetes, she was healthy with no evidence of other metabolic or osseous disease.

The absence of the alveolar calcification is unusual, particularly in the face of rather striking airway calcification. We initially wondered whether the lack of alveolar calcification suggested a nonvisceral pattern of metastatic calcification, but the ratio of Ca:Mg:P resembled that of whitlockite rather than that of hydroxyapatite. Pathologists should not be swayed by the lack of alveolar lesions in distinguishing visceral metastatic calcification in the bronchial tree from either nonvisceral metastatic or dystrophic calcification.

\section{REFERENCES}

1. Ingram P, Shelburne JD, Roggli V. Microprobe analysis in medicine. New York: Hemisphere Publishing Corporation; 1989.

2. Castella J, Puzo C, Cornudella R, Curell R, Tarres J. Tracheobronchopathia osteochondroplastica. Respiration 1981;42:129-34.

3. Heath D, Robertson AJ. Pulmonary calcinosis. Thorax 1977; 32:606-11.

4. Conger JD, Hammond WS, Alfrey AC, Contiguglia SR, Stanford RE, Huffer WE. Pulmonary calcification in chronic dialysis patients. Clinical and pathologic studies. Ann Intern Med 1975;83:330-6.

5. Justrabo E, Genin R, Rifle G. Pulmonary metastatic calcification with respiratory insufficiency in patients on maintenance haemodialysis. Thorax 1979;34:384-8.

6. Bestetti-Bosisio M, Cotelli R, Schiaffino E, Sorgato G, Schmid C. Lung calcification in long-term dialysed patients: a light and electronmicroscopic study. Histopathology 1984;8:69-79.

7. Breitz HB, Sirotta PS, Nelp WB, Ott S, Figley MM. Progressive pulmonary calcification complicating successful renal transplantation. Am Rev Respir Dis 1987;136:1480-2.

8. Contiguglia SR, Alfrey AC, Miller NL, Runnells DE, Le Geros RZ. Nature of soft tissue calcification in uremia. Kidney Int 1973;4:229-35.

9. Alfrey AC, Solomons CC, Ciricillo J, Miller NL. Extraosseous calcification. Evidence for abnormal pyrophosphate metabolism in uremia. J Clin Invest 1976;57:692-9. 